\title{
Clinical significance of NOTCH1 intracellular cytoplasmic domain translocation into the nucleus in gastric cancer
}

\author{
SHINICHIRO SAITO, HIDEYUKI ISHIGURO, MASAHIRO KIMURA, RYO OGAWA, HIROTAKA MIYAI, \\ TATSUYA TANAKA, KOJI MIZOGUCHI and HIROMITSU TAKEYAMA \\ Department of Gastroenterological Surgery, Nagoya City University Graduate School \\ of Medical Sciences, Nagoya, Honshu 467-8601, Japan
}

Received November 11, 2015; Accepted July 13, 2016

DOI: $10.3892 /$ br.2016.723

\begin{abstract}
Recent studies have shown constitutive activation of the Notch signaling pathway in various types of malignancies. However, it remains unclear whether this signaling pathway is activated in gastric cancer. In the present study, the aim was to investigate the role of Notch signaling in gastric cancer by investigating the subcellular localization of Notch-associated proteins in tissue samples from gastric cancer patients. Samples were obtained from 115 gastric cancer patients who had undergone surgery at the Department of Gastroenterological Surgery, Nagoya City University Graduate School of Medical Science without pre-operative chemotherapy or radiation. Subsequently the correlation between translocation of NOTCH1 intracellular cytoplasmic domain (NICD) into the nucleus (as measured by immunostaining) and survival in gastric cancer patients after surgery was investigated. The results were analyzed in reference to the patients' clinicopathological characteristics and the effects of these results on patient prognosis were determined. Significant correlations were observed between NICD nuclear localization and clinicopathological characteristics, such as tumor status (T factor), lymph node status ( $\mathrm{N}$ factor), pathological stage and differentiation status. No significant correlations were observed between NICD nuclear localization and age, gender, tumor location, vein invasion or lymphatic invasion. Patients with $>30 \%$ of cancer cell nuclei positively stained for NICD (as revealed by immunostaining) were associated with a significantly shorter survival following surgery than patients with $<30 \%$ NICD-positive cancer cell nuclei (log-rank test, $\mathrm{P}=0.0194)$. Univariate analysis revealed that among the clinicopathological factors examined, $\mathrm{T}$ factor [risk rate $(\mathrm{RR})=10.870 ; \mathrm{P}=0.0016], \mathrm{N}$ factor $(\mathrm{R} R=41.667$;
\end{abstract}

Correspondence to: Dr Hideyuki Ishiguro, Department of Gastroenterological Surgery, Nagoya City University Graduate School of Medical Sciences, 1 Kawasumi, Mizuho-cho, Mizuho-ku, Nagoya, Honshu 467-8601, Japan

E-mail: h-ishi@med.nagoya-cu.ac.jp

Key words: NOTCH1, immunohistochemistry, gastric cancer
$\mathrm{P}=0.0003)$, lymphatic invasion $(\mathrm{RR}=13.158 ; \mathrm{P}=0.0125)$, vein invasion $(\mathrm{RR}=25.000 ; \mathrm{P}=0.0019)$ and translocation of NICD to the nucleus $(\mathrm{RR}=3.937 ; \mathrm{P}=0.0312)$ were all identified to be statistically significant prognostic factors. However, multivariate analysis revealed that translocation of NICD to the nucleus was not independently associated with an unfavourable prognosis in patients with gastric cancer. The present results suggest that NOTCH1 acts as an oncogene in gastric cancer. It is hypothesized that translocation of NICD into the nucleus may be used as a therapeutic target in gastric cancer.

\section{Introduction}

Gastric cancer is one of the most prevalent types of human cancer. In Japan, 50,000 people succumb due to gastric cancer every year (1). Survival prognoses for patients with gastric cancer remain poor, prompting researchers to continue searching for novel treatment strategies. To develop novel therapeutic options, it is important to understand the molecular mechanisms of gastric cancer.

Previous studies have shown constitutive activation of the Notch signaling pathway in various types of malignancies (2). However, it remains unclear whether this signaling pathway is activated in gastric cancer. The Notch signaling pathway is an evolutionary conserved pathway that is critical in various cellular processes, including cell fate decisions, proliferation, development, adult homeostasis and stem cell maintenance (3-7). NOTCH1 functions as a receptor in this signaling pathway.

The NOTCH1 receptor binds with one of its ligands, which include jagged 1 (JAG1), JAG2, delta-like 1 (Drosophila) (DLL1), DLL3 or DLL4 (2). The notch intracellular cytoplasmic domain (NICD) of the NOTCH receptor is then subjected to processing by proteases [a disintegrin and metalloproteinase (ADAM) protease or $\gamma$-secretase] and subsequently translocates into the nucleus (2). NICD then binds with target proteins to activate downstream targets and promote Notch signaling.

In the present study, immunostaining for NICD was performed in 115 gastric cancer tissue samples collected during gastric surgery to determine the correlation between localization of NICD, clinicopathological characteristics and survival prognoses in gastric cancer patients. 


\section{Materials and methods}

Tissue samples. Tumor tissue samples were obtained from 115 gastric cancer patients (comprising 74 males and 41 females; mean age, 63.1 years) who had undergone surgery at the Department of Gastroenterological Surgery, Nagoya City University Graduate School of Medical Science (Nagoya, Japan) between 1996 and 2007 without pre-operative chemotherapy or radiation. All samples were snap-frozen in liquid nitrogen and stored at $-80^{\circ} \mathrm{C}$. The tumors were classified according to 6 th UICC guidelines for clinical and pathological studies on gastric cancer (8). Written, informed consent was obtained from each patient and approval was obtained from the ethical committee on human research of Nagoya City University (code, no. 71).

Immunohistochemistry. Immunohistochemical staining was performed on gastric cancer tissue samples that were fixed with $10 \%$ formalin for 1 day at room temperature, and then embedded in paraffin. Paraffin-embedded 3- $\mu$ m tumor sections were deparaffinized using xylene (Wako Laboratory Chemicals, Osaka, Japan), rehydrated, and heat-treated by microwaving in $10 \mathrm{mM}$ citrate buffer (Cell Signaling Technology, Tokyo, Japan) for $15 \mathrm{~min}$ for antigen retrieval. The sections were cooled to room temperature and washed three times with phosphate-buffered saline (PBS; Wako Laboratory Chemicals), for 5 min each time. Sections were then treated with $0.3 \% \mathrm{H}_{2} \mathrm{O}_{2}$ in methanol for $30 \mathrm{~min}$ to neutralize endogenous peroxidases, blocked with Block-Ace (Dainihon Sumitomo Seiyaku, Osaka, Japan) for $10 \mathrm{~min}$, and incubated with primary monoclonal antibodies targeting human NOTCH1 (1:50; cat. no. ST1028; Calbiochem; EMD Millipore, Billerica, MA, USA) overnight at $4^{\circ} \mathrm{C}$. The sections were then washed with PBS three times. The sections were incubated with a secondary antibody (1:10; EnVision+ kit; cat. no. K400211: Dako North America, Inc., Carpinteria, CA, USA) for $30 \mathrm{~min}$ and washed with PBS three times. Detection of immunoreactive proteins was facilitated with 3,3'-diaminobenzidine buffer tablets (EMD Millipore) and the sections were counterstained with hematoxylin. For the evaluation of NOTCH1 expression, immunostaining was considered positive only when unequivocally strong nuclear staining was present in $>30 \%$ of the tumor cells, as analyzed using a light microscope. Cases with faint staining only were considered negative.

Statistical analysis. Statistical analysis was performed using the StatView 5.0 software package (Abacus Concepts, Berkeley, CA, USA). $\chi^{2}$ tests were used to analyse the associations between NICD immunostaining and the clinical histopathological parameters of the patients. The survival rate of gastric cancer patients after surgery was examined using the Kaplan-Meier method, and survival times were compared using the log-rank test. Cox regression analysis of factors potentially associated with survival was conducted to identify independent factors that may exert a significant joint effect on survival. All tests were two-tailed and $\mathrm{P}<0.05$ was considered to indicate a statistically significant difference.

\section{Results}

Expression of NICD in gastric cancer. First, NOTCH1 localization was examined by immunostaining. Representative
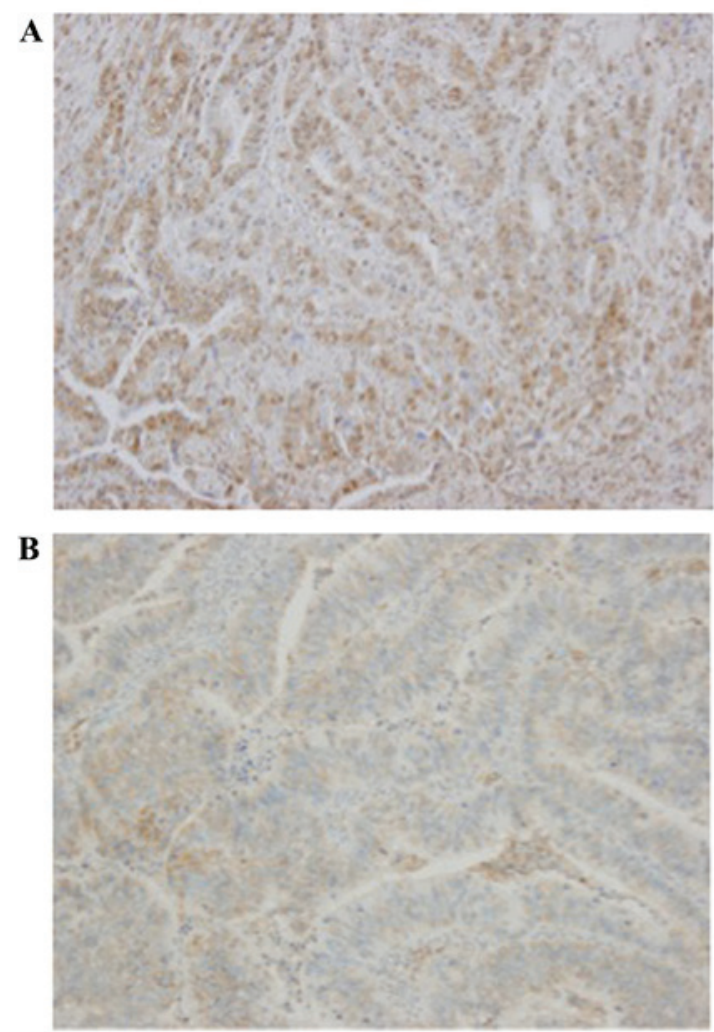

Figure 1. Representative images of NICD immunostaining in gastric cancer tissues (magnification, x100). (A) More than $30 \%$ of cancer cell nuclei were stained positive for NICD. (B) Less than $30 \%$ of cancer cell nuclei were stained for NICD. NICD, NOTCH1 intracellular cytoplasmic domain.

images are presented in Fig. 1. The 115 gastric cancer patients were divided into two groups according to NICD expression: One group of patients exhibited NICD-positive staining in $>30 \%$ of all cancer cell nuclei ( $n=61$; positive group), and the other group had NICD-positive staining in $<30 \%$ of nuclei ( $\mathrm{n}=54$; negative group).

Correlation between clinicopathological factors and NICD in gastric cancer. Correlations between NICD nuclear localization and the clinicopathological characteristics of the patients are presented in Table I. No significant correlation was observed between the NICD-positive group and age, gender, location, lymphatic invasion or blood vessel invasion (Table I). Significant correlations were observed between NICD nuclear localization and clinicopathological characteristics, such as tumor status ( $\mathrm{T}$ factor; $\mathrm{P}=0.0069)$, lymph node status ( $\mathrm{N}$ factor; $\mathrm{P}=0.0118)$, pathological stage $(\mathrm{P}=0.0160)$ and histological differentiation $(\mathrm{P}=0.0232)$.

Survival curves and expression of NICD. The correlation between nuclear localization of NICD and survival time in gastric cancer patients after surgery was investigated, and the mean follow-up was 32.53 months. The NICD-positive group $(n=61)$ had a significantly shorter survival time following surgery when compared with the NICD-negative group $[\mathrm{n}=54$; Fig. $2(\mathrm{P}=0.0194$, log-rank test)].

Among the clinicopathological factors that were evaluated, univariate analysis indicated that local invasiveness [risk rate $(\mathrm{RR})=10.870 ; \mathrm{P}=0.0016]$, lymph node metastasis 
Table I. Correlation of nuclear NICD in gastric cancer with clinicopathological factors, including patient and tumor characteristics $(n=115)$.

\begin{tabular}{|c|c|c|}
\hline Characteristics & $\begin{array}{c}\text { NICD-positive } \\
\text { patients/total patients }\end{array}$ & P-value \\
\hline Age at surgery (years) & & 0.1315 \\
\hline$\leq 65$ & $39 / 66$ & \\
\hline$>65$ & $22 / 49$ & \\
\hline Gender & & 0.4953 \\
\hline Male & $41 / 74$ & \\
\hline Female & $20 / 41$ & \\
\hline Location & & 0.9236 \\
\hline Upper & $15 / 27$ & \\
\hline Middle & $21 / 39$ & \\
\hline Lower & $25 / 49$ & \\
\hline Tumor status & & 0.0069 \\
\hline $\mathrm{T} 1$ & $23 / 57$ & \\
\hline $\mathrm{T} 2$ & $9 / 15$ & \\
\hline $\mathrm{T} 3$ & $9 / 17$ & \\
\hline $\mathrm{T} 4$ & $20 / 26$ & \\
\hline T1 vs. T2-4 & $23 / 57$ vs. $38 / 58$ & \\
\hline Lymph node status & & 0.0118 \\
\hline N0 & $30 / 69$ & \\
\hline N-positive & $31 / 46$ & \\
\hline Pathological stage & & 0.0160 \\
\hline I & $27 / 63$ & \\
\hline II & $13 / 21$ & \\
\hline III & $21 / 31$ & \\
\hline I vs. II-IV & $27 / 63$ vs. $34 / 52$ & \\
\hline Histological differentiation & & 0.0232 \\
\hline Differentiated & $38 / 82$ & \\
\hline Undifferentiated & $23 / 33$ & \\
\hline Lymphatic invasion & & 0.1385 \\
\hline Negative & $20 / 45$ & \\
\hline Positive & $41 / 70$ & \\
\hline Blood vessel invasion & & 0.0786 \\
\hline Negative & $25 / 56$ & \\
\hline Positive & $36 / 59$ & \\
\hline
\end{tabular}

NICD, NOTCH1 intracellular cytoplasmic domain.

( $\mathrm{RR}=41.667 ; \mathrm{P}=0.0003)$, lymphatic invasion $(\mathrm{R}=13.158$; $\mathrm{P}=0.0125)$, vein invasion $(\mathrm{R}=25.00 ; \mathrm{P}=0.0019)$ and $\mathrm{NICD}$ nuclear localization $(\mathrm{RR}=3.937 ; \mathrm{P}=0.0312)$ were statistically significant prognostic factors (Table II). Multivariate analysis revealed that only lymph node metastasis was an independent prognostic factor (Table III).

\section{Discussion}

NOTCH proteins are single-pass transmembrane receptors that regulate cell-fate decisions during development (9). The
Table II. Univariate analysis.

\begin{tabular}{|c|c|c|c|}
\hline Parameters & $\begin{array}{l}\text { Risk } \\
\text { ratio }\end{array}$ & $\begin{array}{c}95 \% \\
\text { confidence } \\
\text { interval }\end{array}$ & P-value \\
\hline \multicolumn{4}{|c|}{ Age at surgery (years) } \\
\hline$\leq 65$ & 1 & & \\
\hline$>65$ & 1.958 & $0.754-5.085$ & 0.1677 \\
\hline \multicolumn{4}{|l|}{ Gender } \\
\hline Male & 1 & & \\
\hline Female & 1.379 & $0.532-3.577$ & 0.5085 \\
\hline \multicolumn{4}{|l|}{ Primary tumor } \\
\hline $\mathrm{T} 1$ & 1 & & \\
\hline $\mathrm{T} 2-4$ & 10.870 & $2.481-47.619$ & 0.0016 \\
\hline \multicolumn{4}{|c|}{ Lymph node metastasis } \\
\hline No & 1 & & \\
\hline N-positive & 41.667 & $5.435-41.667$ & 0.0003 \\
\hline \multicolumn{4}{|l|}{ Lymphatic invasion } \\
\hline Negative & 1 & & \\
\hline Positive & 13.158 & $1.739-100.00$ & 0.0125 \\
\hline \multicolumn{4}{|l|}{ Vein invasion } \\
\hline Negative & 1 & & \\
\hline Positive & 25.000 & $3.289-200.00$ & 0.0019 \\
\hline \multicolumn{4}{|c|}{ Differentiation status } \\
\hline Differentiated & 1 & & \\
\hline Undifferentiated & 3.039 & $1.172-7.874$ & 0.0223 \\
\hline \multicolumn{4}{|l|}{$\begin{array}{l}\text { Immunostaining } \\
\text { for NICD }\end{array}$} \\
\hline Negative & 1 & & \\
\hline Positive & 3.937 & $1.131-13.70$ & 0.0312 \\
\hline
\end{tabular}

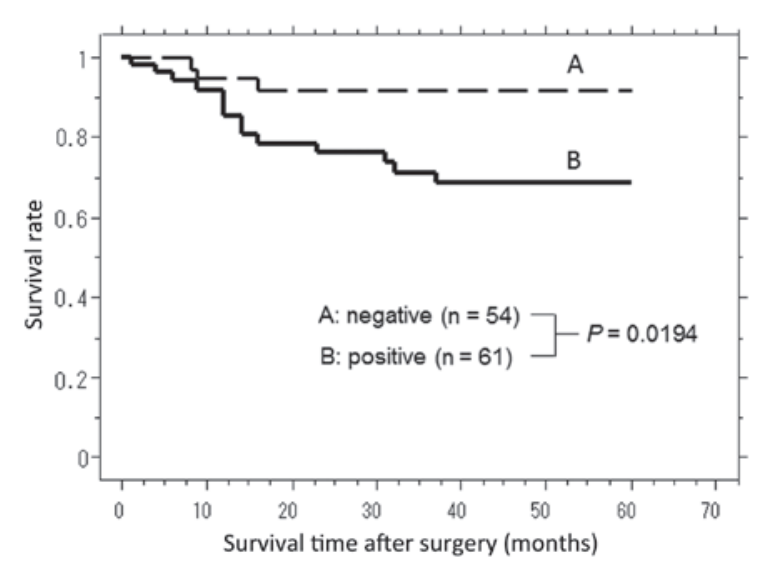

Figure 2. Overall survival rate of patients with gastric cancer according to NICD immunostaining. Patients with $>30 \%$ of cancer cell nuclei positively stained for NICD had a significantly shorter survival time following surgery than patients with $<30 \%$ of nuclei positively stained for NICD $(\mathrm{P}=0.0194)$.

NOTCH family includes four receptors, NOTCH1, NOTCH2, NOTCH3 and NOTCH4, whose ligands include JAG1, JAG2, 
Table III. Multivariate analysis including NICD.

\begin{tabular}{|c|c|c|c|}
\hline Parameters & $\begin{array}{l}\text { Risk } \\
\text { ratio }\end{array}$ & $\begin{array}{c}95 \% \\
\text { confidence } \\
\text { interval }\end{array}$ & P-value \\
\hline \multicolumn{4}{|l|}{ Primary tumor } \\
\hline $\mathrm{T} 1$ & 1 & & \\
\hline $\mathrm{T} 2-4$ & 0.371 & $0.0528-2.618$ & 0.3204 \\
\hline \multicolumn{4}{|c|}{ Lymph node metastasis } \\
\hline No & 1 & & \\
\hline N-positive & 27.778 & $2.632-333.33$ & 0.0056 \\
\hline \multicolumn{4}{|c|}{ Lymphatic invasion } \\
\hline Negative & 1 & & \\
\hline Positive & 0.924 & $0.104-8.197$ & 0.9435 \\
\hline \multicolumn{4}{|l|}{ Vein invasion } \\
\hline Negative & 1 & & \\
\hline Positive & 8.403 & $0.827-83.333$ & 0.0719 \\
\hline \multicolumn{4}{|c|}{ Differentiation status } \\
\hline Differentiated & 1 & & \\
\hline Undifferentiated & 2.933 & $0.946-9.091$ & 0.0623 \\
\hline \multicolumn{4}{|c|}{ Immunostaining for NICD } \\
\hline Positive & 1 & & \\
\hline Negative & 2.0747 & $0.451-9.524$ & 0.3486 \\
\hline
\end{tabular}

NICD, NOTCH1 intracellular cytoplasmic domain.

DLL1, DLL3, and DLL4 (2). The mature NOTCH1 receptor is a heterodimeric class I transmembrane glycoprotein, generated by proteolytic processing of a precursor polypeptide (proNOTCH1) in the trans-Golgi network (10). Receptors bind to their ligand NOTCH receptor, which is then subjected to processing by proteases (ADAM protease and $\gamma$-secretase) and translocate into the nucleus (11). NICD activates its targets, promoting protein-protein interactions (12). Data from the present study revealed that the translocation of NICD into the nucleus occurred in approximately half of the examined gastric cancer cases (53\%; Table I). Therefore, it was hypothesized that the Notch signaling pathway is activated in approximately half of all gastric cancer cases.

Oncogenic roles for Notch signaling have also been discovered in Hodgkin's lymphoma (HL), anaplastic large-cell non-HL, certain types of acute myeloid leukemia and B-cell chronic lymphoid leukemia, gliomas, medulloblastomas, sarcomas, and various epithelial malignancies of the breast, cervix, lung, colon, prostate, head and neck, kidney, and pancreas (13-19). However, while many of the mechanisms underlying the deregulation in these malignancies remain unclear, the altered expression of Notch receptors or other Notch signaling pathway components is often associated with poor prognosis or tumor metastasis (20). Together, these facts indicate that Notch signaling is oncogenic in a variety of types of human tumor. Consistent with this, the present data indicates that NOTCH1 is oncogenic in gastric cancer, as nuclear translocation of NOTCH1 was correlated with the $\mathrm{T}$ and $\mathrm{N}$ factors, and a poor prognosis.
Conversely, Notch signaling is anti-oncogenic in squamous cell carcinoma (SCC) of the skin and cervical uterus, and for basal cell carcinoma (BCC) of the skin (21-23), partially due to its interference with canonical WNT signaling. Thus, it remains unclear whether NOTCH1 acts as a tumor suppressor or oncogene. However, according to the present data, activation of the Notch signaling pathway in gastric cancer is indicated to promote cancer, since NICD expression correlated with tumor status and lymph node metastasis (Table I). Therefore, the present study hypothesizes that NOTCH1 acts as an oncogene in gastric cancer.

The role of the Notch signaling pathway in gastric cancer is particularly complicated, and it is not clear what mechanisms regulate the NOTCH1 signaling pathway. However, a previous study suggested that NOTCH1 signaling contributes to the progression of human gastric cancer through induction of prostaglandin-endoperoxide synthase 2 (PTGS2) expression (24).

The NOTCH1 gene is located on chromosome 9q34. A previous study reported that the most frequent chromosomal changes in gastric adenoma, as analyzed by comparative genomic hybridization, were gains on $9 q(25)$. Thus, amplification of NOTCH1 signaling via chromosomal alterations may be involved in gastric cancer carcinogenesis.

In gastric cancer patients, prognostic markers, including erb-b2 receptor tyrosine kinase 2 (ERBB2) $(26,27)$, $C D 44(28,29)$ and matrix metallopeptidase $12(30)$ have been reported. Additionally, a previous study by the present team demonstrated that the expression of the microRNAs mir-20b and mir-150 may be a prognostic marker for undifferentiated gastric cancer (1). Thus, NOTCH1 may be added to this list of prognostic markers. However, further investigations into the role of NOTCH1 in gastric cancer progression are required. Although the precise molecular mechanisms involved in the activation of the NOTCH1 signaling pathway remain to be clarified, the present data suggest that NOTCH1 may be a molecular target for the development of an effective therapeutic intervention for patients with gastric cancer.

\section{Acknowledgements}

The authors would like to thank Ms. Haruko Izuchi for her excellent technical assistance.

\section{References}

1. Katada T, Ishiguro H, Kuwabara Y, Kimura M, Mitui A, Mori Y, Ogawa R, Harata K and Fujii Y: MicroRNA expression profile in undifferentiated gastric cancer. Int J Oncol 34: 537-542, 2009.

2. Katoh $\mathrm{M}$ and Katoh M: Notch signaling in gastrointestinal tract (Review). Int J Oncol 30: 247-251, 2007.

3. Artavanis-Tsakonas S, Rand MD and Lake RJ: Notch signaling: Cell fate control and signal integration in development. Science 284: 770-776, 1999.

4. Lai EC: Notch signaling: control of cell communication and cell fate. Development 131: 965-973, 2004.

5. Le Borgne R, Bardin A and Schweisguth F: The roles of receptor and ligand endocytosis in regulating Notch signaling. Development 132: 1751-1762, 2005.

6. Bray SJ: Notch signalling: A simple pathway becomes complex. Nat Rev Mol Cell Biol 7: 678-689, 2006.

7. Baron M: An overview of the Notch signalling pathway. Semin Cell Dev Biol 14: 113-119, 2003. 
8. Wang W, Sun XW, Li CF, Lv L, Li YF, Chen YB, Xu DZ, Kesari R, Huang CY, Li W, et al: Comparison of the 6th and 7th editions of the UICC TNM staging system for gastric cancer: results of a Chinese single-institution study of 1,503 patients. Ann Surg Oncol. 18:1060-1067, 2011.

9. Struhl G and Adachi A: Requirements for presenilin-dependent cleavage of notch and other transmembrane proteins. Mol Cell 6: 625-636, 2000

10. Sulis ML, Williams O, Palomero T, Tosello V, Pallikuppam S, Real PJ, Barnes K, Zuurbier L, Meijerink JP and Ferrando AA: NOTCH1 extracellular juxtamembrane expansion mutations in T-ALL. Blood 112: 733-740, 2008.

11. Kopan R and Ilagan MX: The canonical Notch signaling pathway: unfolding the activation mechanism. Cell 137: 216-233, 2009

12. Brzozowa M, Mielańczyk L, Michalski M, Malinowski L, Kowalczyk-Ziomek G, Helewski K, Harabin-Słowińska M and Wojnicz R: Role of Notch signaling pathway in gastric cancer pathogenesis. Contemp Oncol (Pozn) 17: 1-5, 2013.

13. Leong KG and Karsan A: Recent insights into the role of Notch signaling in tumorigenesis. Blood 107: 2223-2233, 2006.

14. Koch U and Radtke F: Notch and cancer: a double-edged sword Cell Mol Life Sci 64: 2746-2762, 2007.

15. Miele L: Notch signaling. Clin Cancer Res 12: 1074-1079, 2006.

16. Miele L, Miao $\mathrm{H}$ and Nickoloff BJ: NOTCH signaling as a novel cancer therapeutic target. Curr Cancer Drug Targets 6: 313-323, 2006

17. Wang Z, Banerjee S, Li Y, Rahman KM, Zhang Y and Sarkar FH: Down-regulation of notch-1 inhibits invasion by inactivation of nuclear factor-kappaB, vascular endothelial growth factor, and matrix metalloproteinase-9 in pancreatic cancer cells. Cancer Res 66: 2778-2784, 2006.

18. Zhu H, Zhou X, Redfield S, Lewin J and Miele L: Elevated Jagged-1 and Notch-1 expression in high grade and metastatic prostate cancers. Am J Transl Res 5: 368-378, 2013.

19. Yang Y, Yan X, Duan W, Yan J, Yi W, Liang Z, Wang N, Li Y, Chen W, Yu S, et al: Pterostilbene exerts antitumor activity via the Notch1 signaling pathway in human lung adenocarcinoma cells. PLoS One 8: e62652, 2013

20. Lee SH, Jeong EG, Yoo NJ and Lee SH: Mutational analysis of NOTCH1, 2, 3 and 4 genes in common solid cancers and acute leukemias. APMIS 115: 1357-1363, 2007.
21. Radtke F and Raj K: The role of Notch in tumorigenesis: oncogene or tumour suppressor? Nat Rev Cancer 3: 756-767, 2003.

22. Thélu J, Rossio P and Favier B: Notch signalling is linked to epidermal cell differentiation level in basal cell carcinoma, psoriasis and wound healing. BMC Dermatol 2: 7, 2002.

23. Proweller A, Tu L, Lepore JJ, Cheng L, Lu MM, Seykora J, Millar SE, Pear WS and Parmacek MS: Impaired notch signaling promotes de novo squamous cell carcinoma formation. Cancer Res 66: 7438-7444, 2006

24. Yeh TS, Wu CW, Hsu KW, Liao WJ, Yang MC, Li AF, Wang AM, Kuo ML and Chi CW: The activated Notch1 signal pathway is associated with gastric cancer progression through cyclooxygenase-2. Cancer Res 69: 5039-5048, 2009.

25. Buffart TE, Carvalho B, Mons T, Reis RM, Moutinho C, Silva P, van Grieken NC, Vieth M, Stolte M, van de Velde CJ, et al: DNA copy number profiles of gastric cancer precursor lesions. BMC Genomics 8: 345, 2007.

26. Jørgensen JT and Hersom M: HER2 as a prognostic marker in gastric cancer - a systematic analysis of data from the literature. J Cancer 3: 137-144, 2012.

27. Gravalos $\mathrm{C}$ and Jimeno A: HER2 in gastric cancer: A new prognostic factor and a novel therapeutic target. Ann Oncol 19: $1523-1529,2008$

28. Doventas A, Bilici A, Demirell F, Ersoy G, Turna H and Doventas Y: Prognostic significance of CD44 and c-erb-B2 protein overexpression in patients with gastric cancer. Hepatogastroenterology 59: 2196-2201, 2012.

29. Yamamichi K, Uehara Y, Kitamura N, Nakane Y and Hioki K: Increased expression of CD44v6 mRNA significantly correlates with distant metastasis and poor prognosis in gastric cancer. Int $\mathbf{J}$ Cancer 79: 256-262, 1998

30. Zheng J, Chu D, Wang D, Zhu Y, Zhang X, Ji G, Zhao H, Wu G, $\mathrm{Du} \mathrm{J}$ and Zhao Q: Matrix metalloproteinase-12 is associated with overall survival in Chinese patients with gastric cancer. J Surg Oncol 107: 746-751, 2013 